UNIVERSITA’ DEGLI STUDI DI BERGAMO

DIPARTIMENTO DI INGEGNERIA GESTIONALE

QUADERNI DEL DIPARTIMENTO ${ }^{\dagger}$

Department of Economics and Technology Management

Working Paper

n. $04-2009$

A comparative study of airport connectivity in China, Europe and US:

which network provides the best service to passengers?

by

Stefano Paleari, Renato Redondi, Paolo Malighetti

${ }^{\dagger}$ Il Dipartimento ottempera agli obblighi previsti dall’art. 1 del D.L.L. 31.8.1945, n. 660 e successive modificazioni. 


\section{COMITATO DI REDAZIONE ${ }^{\S}$}

Lucio Cassia, Gianmaria Martini, Stefano Paleari, Andrea Salanti

\footnotetext{
${ }^{\S}$ L'accesso alla Collana dei Quaderni del Dipartimento di Ingegneria Gestionale è approvato dal Comitato di Redazione. I Working Papers della Collana costituiscono un servizio atto a fornire la tempestiva divulgazione dei risultati dell'attività di ricerca, siano essi in forma provvisoria o definitiva.
} 


\title{
A comparative study of airport connectivity in China, Europe and US: which network provides the best service to passengers?
}

\author{
Stefano Paleari*, Renato Redondi**, Paolo Malighetti*** \\ * Department of Economics and Technology Management, University of Bergamo, Scientific \\ Director of ICCSAI, Viale G.Marconi, 5 - 24044 Dalmine (BG) Italy \\ ** Department of Mechanic Engineering, University on Brescia, Italy \\ *** Department of Economics and Technology Management, University of Bergamo, Italy; \\ Tel. +39035 2052023 - Fax. +3902 700423094; e-mail paolo.malighetti@unibg.it
}

\begin{abstract}
This paper investigates the connectivity of the airport networks in China, Europe and US. Our aim is to analyze which network is most beneficial to final passengers in terms of travel time and which of the network features lead to such a result. A time-dependent minimum path approach is employed to calculate the minimum travel time between each pair of airports in the three networks, inclusive of flight times and waiting times in intermediate airports. We evaluate each fastest indirect connection in terms of circuitry times and routing factors to consider the effect of the hubs' locations. Then we assess the temporal coordination of flights by calculating the average waiting times in intermediate airports. Our results show that fastest connections do not differ much in terms of routing factors and circuitry times. Even if the European network has the greater number of direct flights per airport, when connections require intermediate airports, their average waiting times exceed those of the American and Chinese Network.
\end{abstract}

Keywords: 1) Airport connectivity, 2) Network features, 3) travel time 


\section{Introduction}

The air transportation network has an enormous impact on economies, social evolution and community welfare at the local, national, and international levels. This is confirmed by the attention paid by policy-makers and the media to problems with its efficiency and safety. It is thus interesting to investigate and compare different airport networks in terms of the features and connectivity they offer. Moreover, the ongoing growth and liberalization of air transport systems worldwide have spurred rapid development of the industry.

While not yet at the point of a "single playfield", liberalization has already increased the size of several common aviation areas. Among the biggest are the US domestic market and the European common aviation area. The Chinese network is also interesting in terms of size and recent growth. These networks account for $51.1 \%$ of all seats offered worldwide (see Table 1). The three networks are also subject to homogeneous internal aviation laws developed differently. Finally, they all present complex dynamics similar to the worldwide airport network. The aim of this paper is to compare the features and connectivity offered by the three major networks, and to discover the reasons behind any differences.

\begin{tabular}{lrrr}
\hline Airport network & $\begin{array}{r}\text { \% of routes } \\
\text { worldwide }\end{array}$ & $\begin{array}{r}\text { \% of flights } \\
\text { worldwide }\end{array}$ & $\begin{array}{r}\text { \% of seats offered } \\
\text { worldwide }\end{array}$ \\
\hline \hline US domestic & $19.0 \%$ & $28.4 \%$ & $22.2 \%$ \\
EU domestic + intra EU & $22.3 \%$ & $22.8 \%$ & $23.9 \%$ \\
Chinese domestic & $4.9 \%$ & $4.4 \%$ & $5.0 \%$ \\
\hline overall & $46.2 \%$ & $55.6 \%$ & $51.1 \%$ \\
\hline
\end{tabular}

Table $\overline{1 . \text { The sizes of three local networks compared to the overall worldwide network. Source: our analysis of the }}$ Innovata database. The data refer to flights scheduled for 24 October 2007.

\section{Literature review}

In the framework of network analysis, airports represent nodes and individual routes represent the connections between them. The resulting structure is interesting in terms of both topological features and what it reveals about network performance from the passenger's perspective. The first topic draws from the literature on complex networks, while the second falls under the topic of air transport economics and evolution. 
An airport network's topology can be analyzed by employing graph theory. The field of complex network analysis has developed powerful tools for studying integrated structures and their dynamics. The main characteristics of a network can be inferred from its $\mathrm{N} \times \mathrm{N}$ adjacency matrix $(\mathrm{N}$ being the number of nodes) whose elements $a_{i j}$ are 1 if node $i$ and node $j$ are connected, and 0 otherwise. Another $\mathrm{N} \times \mathrm{N}$ matrix contains the weight of each connection, which in the context of aviation may well be the distance of the route. Typical measures characterizing a network are the distribution degree (the typical number of edges starting from a node) and the clustering coefficient (quantifying the connectivity among immediate neighbors).

Recent advances by Watts and Strogatz (1998), Barabási and Albert (1999), Amaral et al. (2000), and Albert and Barabási (2002) have boosted the scope of complex network theory. They defined the concept and features of a "small world network". Furthermore, Costa and Silva (2006) found that the distribution degree allows one to define a node hierarchy, leading to a taxonomy of relationships between the nodes. Guimerà et al. (2007) divided complex networks into two distinct functional classes on the basis of their connection frequency. The topology of a network is strictly related to the dynamics of its formation (Watts and Strogatz, 1998; Watts, 1999). For this reason, growth determinants and future evolution may be inferred from a network's current topology (Barrat et al., 2004).

Previous studies have classified airport systems as small world, scale-free networks (Guimerà et al. 2005; Bagler, 2004; Li and Cai, 2004). This means that new links are more likely to be appended to nodes with higher connectivity, yielding a power law distribution of airport degrees.

Capacity saturation and political barriers partially distort the actual network topology from the theoretical one. Guimerà et al. (2005), analyzing the worldwide airport network, found that the most central cities are not always the most connected for political reasons. Bagler (2004) found that the Indian airport network is of the small world type, but that the incremental cost of additional capacity in bigger airports truncates the scale-free power law distribution. Li and Cai (2004) classified the topology of the Chinese airport network as intermediate between a random graph and a scale-free network. Analyzing the Italian airport network, Guida and Funaro (2007) detected a small world, scale-free network with fractal structure.

One of the main features of a network is its mobility (Milgram, 1977), defined as the ease of traveling from one node to another. Mobility measures are based on the minimum path between any given pair of nodes. In the simplest case, they may represent the number of steps needed to travel from one node to another. In more complex cases, each step is weighted by one or more proxies for 
the importance of nodes and edges. In the field of airport networks, connections may be weighted by frequency of operation, number of seats offered, or geographical distance.

Latora and Marchiori (2001) introduced the related concept of efficiency, which measures how easily information is exchanged over the network. In the field pf airport networks, Latora and Marchiori definition of efficiency is represented by the extra distance involved in the shortes path between any airport pairs compared to the direct distance. An efficiency of 1 is possible only when each node is connected to every other. Latora and Marchiori (2001) showed that small-world networks are highly efficient. A similar efficiency measure is employed by Li and Cai (2004) in their analysis of the Chinese airport network, obtaining a score of 0.484 .

Following these definitions, a network is efficient when travel within it is equally easy in any direction, with no reference to overall costs or unit costs. This property might better be called the effectiveness or feasibility of a network.

The main drawback of complex network analysis is its failure to take into account the temporal coordination of airport networks. In many cases, the additional utility derived from connecting to a high-degree airport is the chance to use this airport as an intermediate step to other destinations. But an interconnection is really feasible only if incoming and outgoing flights at the intermediate airport occur within a reasonably narrow window. Veldhius (1997), Burghouwt and de Wit (2005), and Burghouwt (2007) measured the number of flights that can be interconnected considering a time windows between arrival and departure ranging from 45 minutes up to 3 hours. Both studies developed an index of indirect connectivity between hub airports and worldwide destinations. Other studies (Bagler, 2004, Li and Cai, 2004) have tried to consider temporal coordination by weighting the airport network by frequency. Both approaches essentially evaluate the number of connections that a passenger passing through the airport could exploit. However, note that many of these connections will not lie on the quickest path towards a passenger's final destination. Malighetti et al. (2008) overcame this problem by computing minimum paths in terms of the quickest travel time between any pair of airports as a function of departure hour, including both flight time and waiting time in intermediate airports. The present paper takes a similar approach to calculating travel times,

but uses this information to compare the effective mobility granted by the Chinese, European and US networks.

\section{Methodology}

The goal of this paper is to compare the structure and performance of the three airport networks. Minimum paths in the networks are calculated in terms of minimum travel time between nodes, including both flight time and waiting time in intermediate airports, and are assumed to depend on 
the passenger's departure hour. This methodology, based on the theoretical work of Miller-Hooks and Patterson (2004), was recently employed in Malighetti et al. (2008) to quantify the effectiveness of the self-help hubbing strategy in the European network.

In order to guarantee the feasibility of connections and the reliability of travel times, we consider only scheduled flights operating on a specific and typical day in the autumn schedule: Wednesday, the $24^{\text {th }}$ of October 2007.

The minimum waiting times at intermediate airports may be influenced by several factors: the presence of dedicated facilities to manage transfer passengers, the degree of airport congestion, and the airport's overall size. In this paper we assume a minimum interconnecting period of 60 minutes for all intermediate airports. This lower limit does not apply in the case of multi-leg trips coordinated directly by a carrier or an alliance, for which the passenger has just one ticket to their final destination. In such cases we take the interconnection waiting period directly from the flight's schedule. In some cases the waiting periods for a multi-leg trip can be less than 45 minutes, especially in small intermediate airports and flights where connecting passengers do not leave the aircraft.

In other cases a 60-minute minimum interconnecting period is acceptable since we aim to compare the internal connections of the three major networks; no intercontinental flights are included in the study. No maximum connecting time is assumed.

As described in Malighetti et al. (2008), the shortest travel time $\operatorname{STT}_{\mathrm{ijt}}$ from airport $\mathrm{i}$ to airport $\mathrm{j}$ is calculated starting at a specified time t. The day is divided into 96 units of fifteen minutes, so starting times range from 00:00 to 23:45. For the European network we work in Brussels time, for the US network we work in New York time, and for the Chinese network we work in Beijing time. Itineraries ending after midnight are not taken into account. Thus, for every possible combination of two airports at a given starting time $t$, we calculate the shortest travel time for all itineraries leaving as early as 00:00 and concluding before midnight of the same day. The minimum travel time from airport $\mathrm{i}$ to $\mathrm{j}$ is then defined as $\mathrm{STT}_{\mathrm{ij}}=\min _{\mathrm{t}}\left(\mathrm{STT}_{\mathrm{ijt}}\right)$.

After calculating the shortest travel times within each network, we investigate their determinants to explain possible differences. In particular, we would like to evaluate the impact of the following three variables: i) connection distance, ii) the relative position of intermediate airports, and iii) waiting time in intermediate airports.

The first factor is simply defined as the geographical distance between the origin airport and the final destination airport. The second and third factors are relevant only to connections requiring more than one flight. Thus, to quantify the effect of an intermediate airport on the route, we 
consider both routing factors (the ratio between indirect and direct flight distances) and circuitry times (the ratio between total flight time and the flight time supposing to fly directly between the departure and destination airports).

To evaluate the overall impact of a given airport on waiting times, we need to know how many quickest paths pass through it, when passengers arrive, and what time the flights to their final destinations actually depart. In other words, further analysis is required to assess the temporal coordination of flights at intermediate airports. The first factor is given by the betweenness of each airport, as described in Freeman (1977) and Malighetti et al. (2008). We define the routing factor as the ratio between in-flight distance and potential direct flight distance. In this paper, we consider only itineraries with a routing factor of at most 1.25. This upper limit excludes indirect connections with excessive detours, even if they are among the shortest possible routes between airports.

As is usual for research focusing on travel times, our work neither assesses traveler utility nor models the passenger's choice of route and airports. To do so would entail a much more complex set of variables, including fares.

\section{Data}

All our data refer to flights scheduled on 24 October 2007, as published in the Innovata database's winter 2007 release. By analyzing a specific day, we consider actual projected connections rather than an average daily schedule with only theoretical significance. In particular, the latter would not guarantee the feasibility of all connections. The specific day was chosen to avoid demand peaks. We include all airports with at least one scheduled flight to another airport of the network. The European network includes all countries of the EU25 plus Switzerland, Norway and Iceland. The US network contains 657 airports, the European network 467 airports, and the Chinese network 143 airports.

Each network is of course connected to the global airport system. Nevertheless, the majority of routes offered occur entirely within each network. This is particularly true of the US network, where $82.3 \%$ of routes are domestic (Table 2). In the present analysis, we only consider internal connections.

Figure 1 represents the three networks on the day considered. While the US network has the most nodes, the European network has the most direct connections. The structures of the networks are clearly quite different: in Europe the major airports are all close to one other, while in US and China they are quite dispersed. 


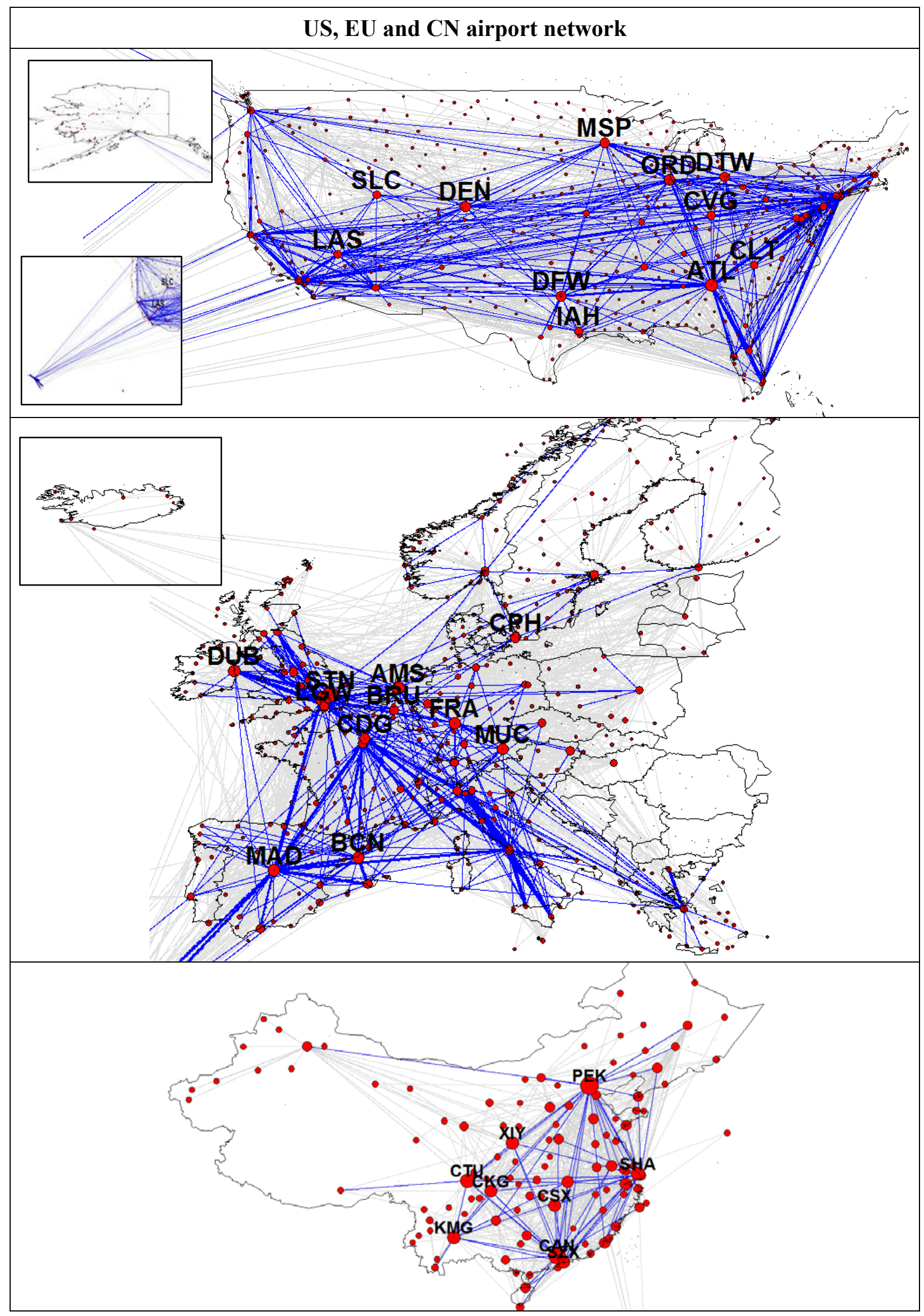

Figure 1.The airport networks of the US, the EU and China. The bright blue lines are drawn for $10 \%$ of routes in each network, those offering the greatest number of seats. 
Figure 2 provides histograms of the $\mathrm{N} \times(\mathrm{N}-1)$ distances $(\mathrm{N}$ being the number of nodes in each network) between airport pairs in each network. In Europe, connection distances are concentrated around 1000-1200 km with a bell-shaped distribution close to Gaussian. In China the relative dispersion of distances is far greater, but the Gaussian distribution is still a reasonable description of the data. The US network, in stark contrast, has several peaks. The two strongest lie around 1000$1200 \mathrm{~km}$ and $4500 \mathrm{~km}$, and are mainly related to travel between airports on the same coast and opposite coasts respectively.

The three networks appear more similar when only direct flights are included in the distribution (see Figure 3). All three networks have a strong peak at about $600-800 \mathrm{~km}$, and a secondary peak at greater distances (3000-4000 km). We suggest two possible explanations for this behavior. The first is simply that local hubs may play the role of bridges between widely separated areas. Second, this structure supports the theory that distances influence the dynamic evolution of a network. In other words, a new edge is more likely to be added between close nodes, at least up to a certain threshold.

\begin{tabular}{lccccc}
\hline $\begin{array}{l}\text { Airport } \\
\text { network }\end{array}$ & $\begin{array}{c}\text { No. of } \\
\text { airports } \\
\text { (nodes) }\end{array}$ & $\begin{array}{c}\text { Average } \\
\text { distance between } \\
\text { airport pairs } \\
(\mathbf{k m})\end{array}$ & $\begin{array}{c}\text { No. of routes } \\
\text { within network }^{\boldsymbol{a}}\end{array}$ & $\begin{array}{c}\text { Avequency of } \\
\text { intra-network } \\
\text { routes }\end{array}$ & $\begin{array}{c}\text { \% of intra- } \\
\text { network routes }\end{array}$ \\
\hline \hline US & 657 & 2954 & 5488 & 4.8 & $82.3 \%$ \\
EU & 467 & 1736 & 5544 & 3.1 & $73.4 \%$ \\
CN & 144 & 1631 & 1329 & 3.3 & $75.1 \%$ \\
${ }^{a}$ one-way routes & & & & & \\
\hline
\end{tabular}

Table 2. Summary statistics on the three local networks. 


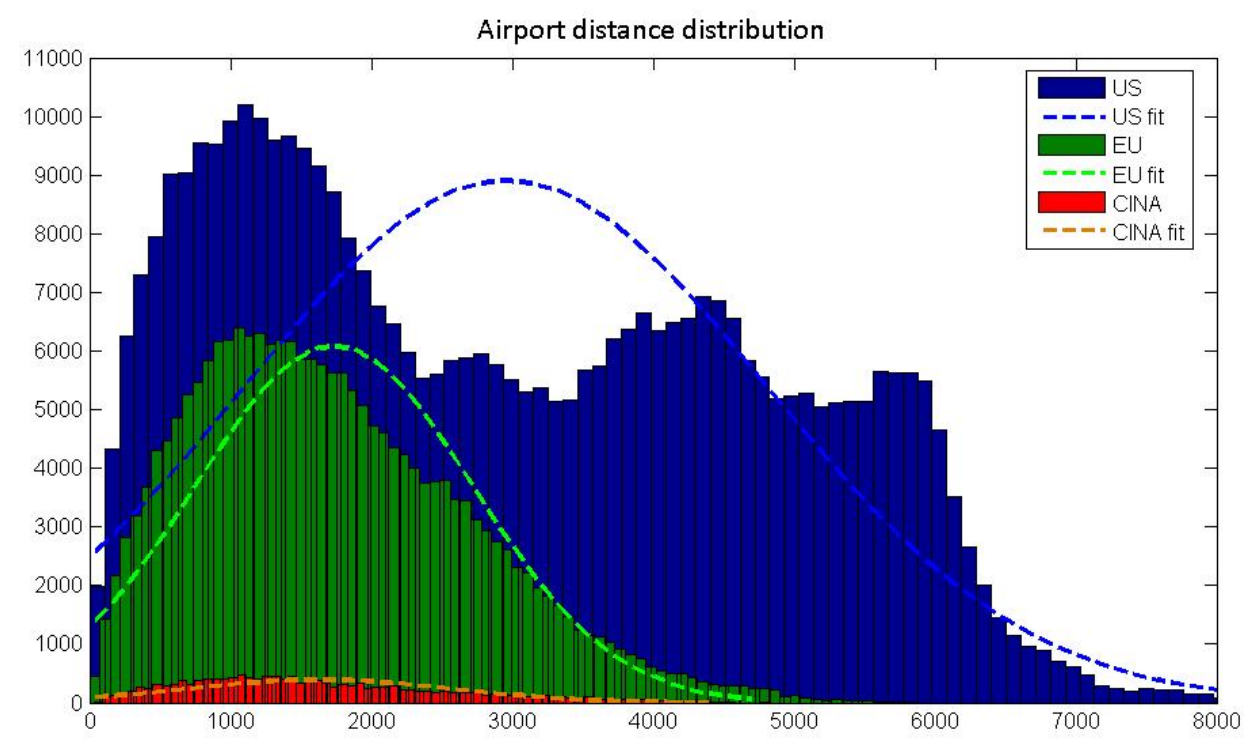

Figure 2. Histograms of the $N \times(N-1)$ distances between airport pairs in the three networks ( $N$ is the number of nodes in each network). The dashed curves represent best-fit Gaussian distributions to the data.

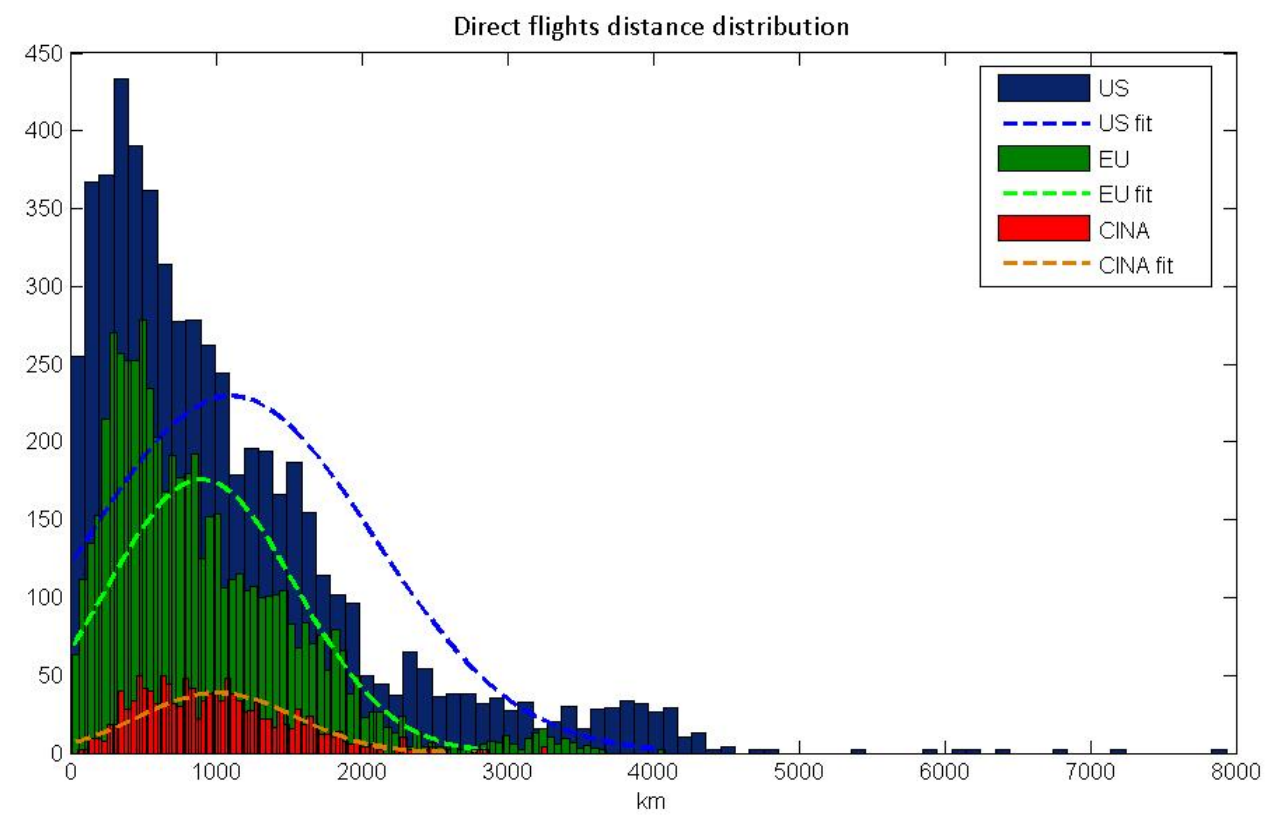

Figure 3. Histograms of the direct flight distances (edges) in each network. 


\section{Empirical analysis}

\subsection{Network topology}

Our topological analysis confirms that all three airport systems belong to the class of small world networks. Their configurations are similar to the scale-free power law, but are better fit by a double Pareto law (Reed, 2003):

$$
\begin{cases}P(>k)=c_{1}+k^{-\alpha_{1}}+\varepsilon_{1} & k \leq k_{c} \\ P(>k)=c_{2}+k^{-\alpha_{2}}+\varepsilon_{2} & k>k_{c}\end{cases}
$$

where $k$ is the airport's degree. The European network (see Table 3 and Figure 4) has the highest values of $\alpha 1$ and $\alpha 2$, meaning its degree distribution decays more rapidly. One possible explanation for this difference is that Europe experiences more congestion than the other two regions. The average shortest path length ranges from 2.34 steps in China to 3.38 steps in the US. In all three cases, the average shortest path length is very close to that of a comparable random network (with the same number of nodes and edges). Their clustering coefficients (the probability that two airports connected with a third one is also direct connected each other), however, are all significantly higher than those of comparable random networks. Despite the emergence of a point-to-point structure and greater average degree due to the rise of low-cost carriers, the European network still has the lowest clustering coefficient.

\begin{tabular}{|c|c|c|c|c|c|c|c|c|}
\hline \multirow[b]{2}{*}{$\begin{array}{l}\text { Airport } \\
\text { network }\end{array}$} & \multirow[b]{2}{*}{$\begin{array}{c}\text { Average } \\
\text { degree }\end{array}$} & \multicolumn{2}{|c|}{ Average SPL } & \multicolumn{2}{|c|}{ Clustering coeff. } & \multirow[b]{2}{*}{$\begin{array}{c}\text { Critical } \\
\text { degree } \\
k_{c}\end{array}$} & \multirow[b]{2}{*}{$\begin{array}{c}\alpha 1 \\
\left(k \leq k_{c}\right)\end{array}$} & \multirow[b]{2}{*}{$\begin{array}{c}\alpha 2 \\
\left(k>k_{c}\right)\end{array}$} \\
\hline & & measured & $\begin{array}{c}\sim(\text { rnd } \\
\text { network) }\end{array}$ & measured & $\begin{array}{c}\sim(\text { rnd } \\
\text { network })\end{array}$ & & & \\
\hline US & 8.5 & 3.38 & 2.80 & 0.45 & 0.017 & 77 & 0.72 & -3.99 \\
\hline EU & 12.1 & 2.80 & 2.45 & 0.38 & 0.027 & 60 & 0.80 & -4.23 \\
\hline Chinese & 9.2 & 2.34 & 2.14 & 0.49 & 0.074 & 28 & 0.51 & -2.79 \\
\hline
\end{tabular}

Table 3. Network topology statistics. Columns 4 and 6 report the average shortest path length and the clustering coefficient of a comparable network (same number of edge and nodes) with a random edge distribution. 


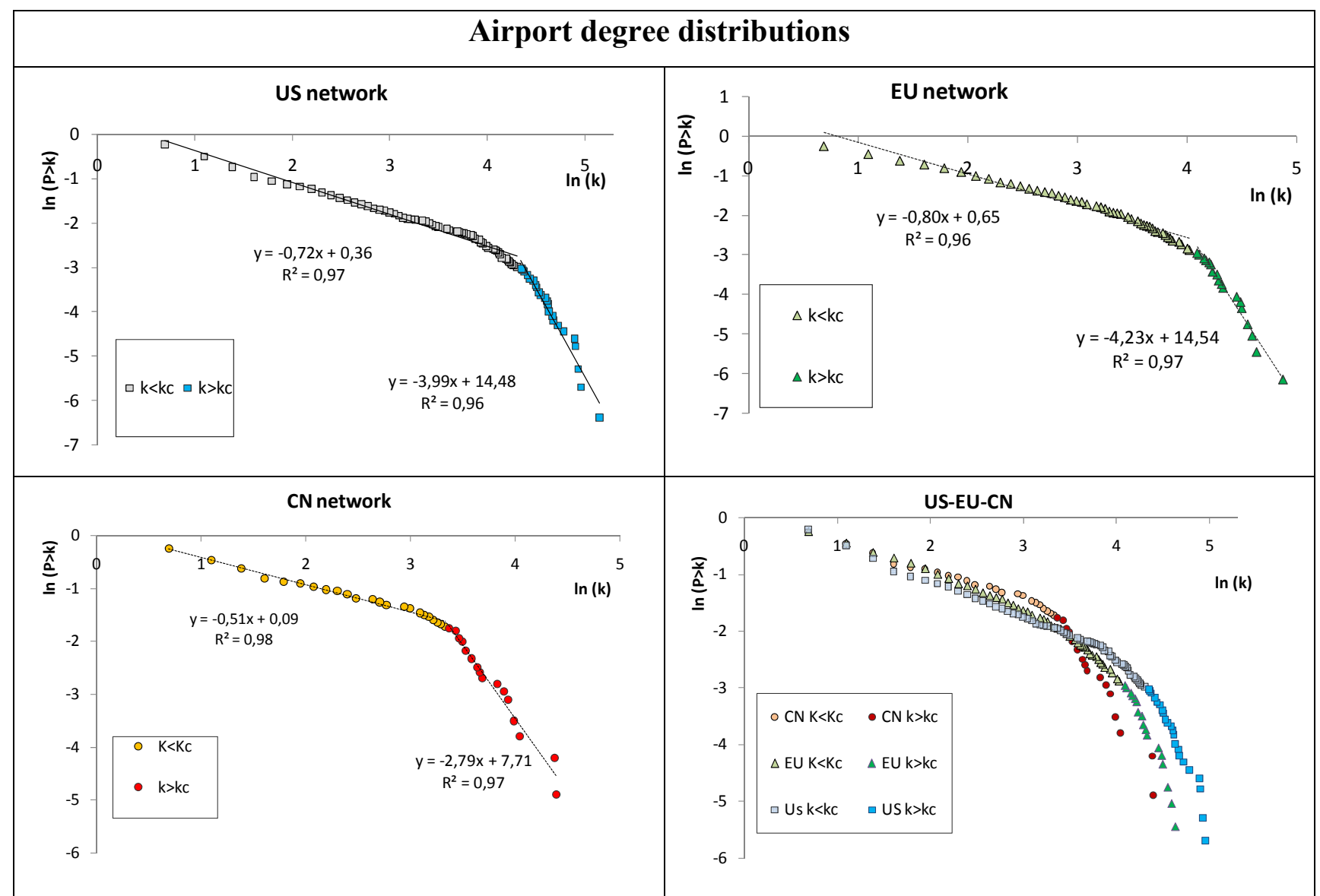

Figure 4. Degree distributions of the three networks. In all three cases the 'knee' of the Pareto double power law distribution is clearly visible in the data. The fourth panel (lower right) superposes the three distributions.

\subsection{Travel time analysis}

As mentioned at the end of Section 2, any analysis of network topology will fail to take into account the temporal coordination of flights. We now consider the average time required to go from a given node to any other node in the network. We also evaluate the average number of steps required to complete the connections, the quickest connecting path as a function of departure time, and the routing factors and waiting times associated with the intermediate airports (see Section 3 for a definition of these quantities).

Departure times for the flights considered range from 6.00 to 23:45. Where available, direct connections are clearly the shortest travel time option. The case of indirect connections is more complicated: earlier departures increase the chance of making a connection, but also tend to increase waiting times. For each airport, we begin by finding the departure time that minimizes the average travel time to all destinations reachable by midnight of the same day. For airport $i$ this quantity is the $\mathrm{t}$ which minimizes $\Sigma_{\mathrm{j}} \mathrm{STT}_{\mathrm{ijt}} / \mathrm{N}$. 
For the majority of the airports in the three networks, as shown in Figure 5, the best departure time is between 10:30 AM and 12:00 A.M. In the next part of the analysis we consider for each airport pairs the best shortest travel time available during the day.

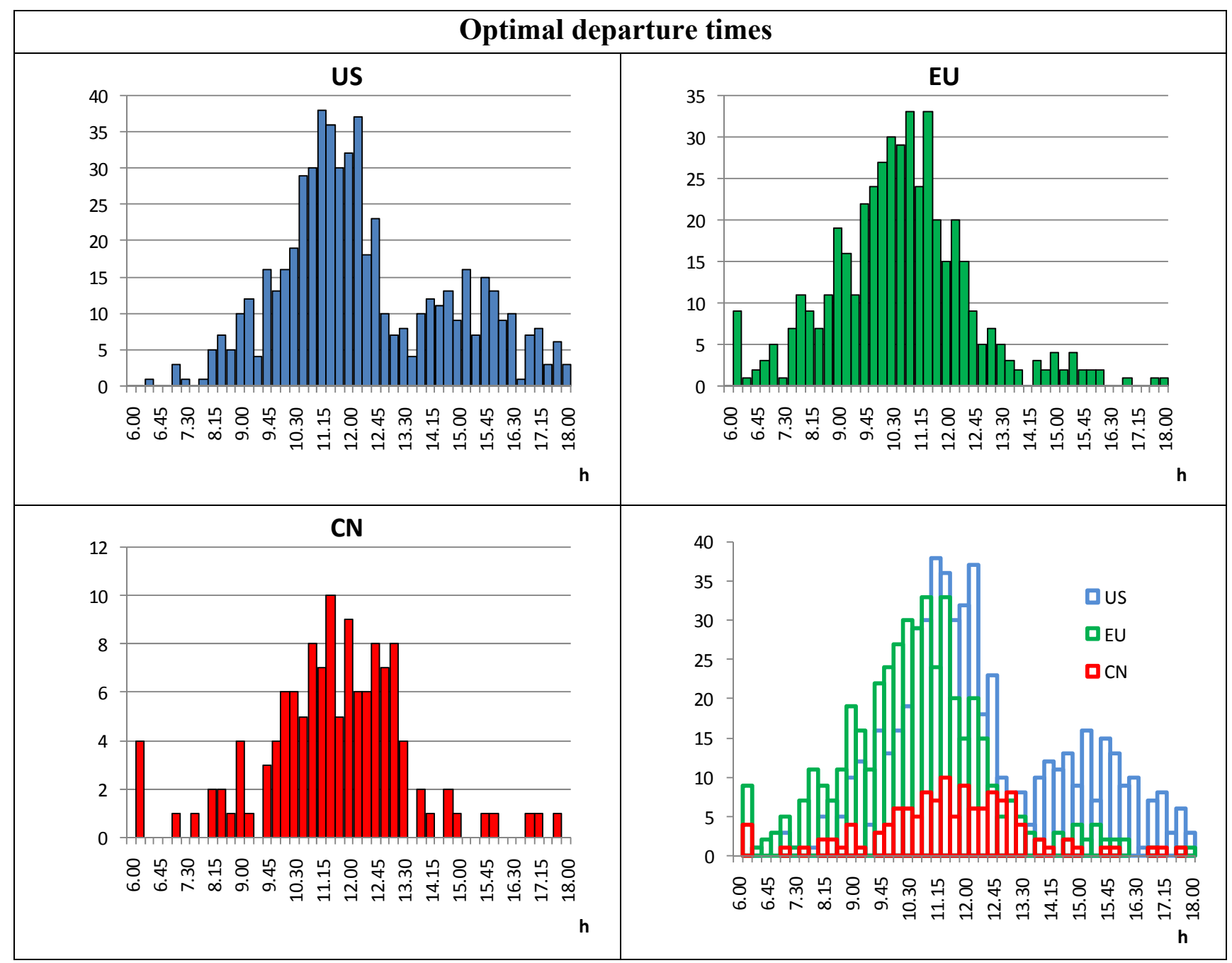

Figure 5. Distributions of optimal departure times (minimizing the average shortest travel time from each airport in the network to all other airports).

If $\mathrm{N}$ is the number of airports in the network, there are $\mathrm{N} \times(\mathrm{N}-1)$ possible one-way connections between airports. We find that $39.1 \%$ of the $\mathrm{N} \times(\mathrm{N}-1)$ theoretical connections in Europe can be successfully completed by midnight, compared to $28.2 \%$ in the US and $29.3 \%$ in China. We call this index "network openness". This measure is influenced by the upper limit of 1.25 we placed on routing factors. Even without a routing factor limit, however, in all three networks fewer than half of theoretical connections can be completed within the analyzed day. The European network has the highest "openness" both with and without a routing factor limit, due to its large number of short direct routes. Despite having a higher average frequency overall, longer distances penalize the US network in terms of "openness". 
Table 4 reports on other features of the quickest paths between airport pairs as a function of the number of steps involved. In the US and EU, two- and three-step routes account for $75.0 \%$ and $66.7 \%$ of all fastest connections respectively. As previously remarked, the EU offers more direct flights and more complex multi-step paths. The Chinese network has the highest percentage of direct flights. This feature is explained by its smaller size, as shown in Figure 6 a small size generate an higher share of direct flights being equal the average degree. In Europe and the US, a high level of three-step connections suggests the presence of local hubs; in China, almost half of the fastest connections have two steps.

\begin{tabular}{|c|c|c|c|c|c|}
\hline $\begin{array}{l}\text { No. } \\
\text { steps }\end{array}$ & $\begin{array}{c}\text { No. of origin- } \\
\text { destination pairs }\end{array}$ & $\begin{array}{c}\% \text { of origin- } \\
\text { destination } \\
\text { pairs }\end{array}$ & $\begin{array}{c}\text { Average great } \\
\text { circle distance } \\
(\mathbf{k m})\end{array}$ & $\begin{array}{l}\text { Average routing } \\
\text { factor }\end{array}$ & $\begin{array}{c}\text { Average } \\
\text { circuitry time } \\
\text { (minutes) }\end{array}$ \\
\hline \multicolumn{6}{|c|}{ US airport network } \\
\hline 1 & 5488 & $4.52 \%$ & 1022.3 & - & - \\
\hline 2 & 41833 & $34.48 \%$ & 1747.2 & 1.07 & 15.4 \\
\hline 3 & 49191 & $40.54 \%$ & 2529.5 & 1.11 & 35.1 \\
\hline 4 & 19760 & $16.29 \%$ & 2843.4 & 1.12 & 56.4 \\
\hline 5 & 4286 & $3.53 \%$ & 2991.7 & 1.13 & 77.0 \\
\hline 6 & 526 & $0.43 \%$ & 2441.2 & 1.12 & 102.9 \\
\hline 7 & 157 & $0.13 \%$ & 2207.6 & 1.09 & 110.1 \\
\hline 8 & 79 & $0.07 \%$ & 2903.3 & 1.07 & 117.1 \\
\hline 9 & 12 & $0.01 \%$ & 2173.3 & 1.09 & 139.3 \\
\hline \multicolumn{6}{|c|}{ European airport network } \\
\hline 1 & 5544 & $6.68 \%$ & 891.7 & - & - \\
\hline 2 & 23042 & $27.75 \%$ & 1429.7 & 1.07 & 20.6 \\
\hline 3 & 32312 & $38.92 \%$ & 1978.9 & 1.11 & 38.6 \\
\hline 4 & 15795 & $19.02 \%$ & 2345.1 & 1.13 & 52.7 \\
\hline 5 & 4576 & $5.51 \%$ & 2597.1 & 1.13 & 61.8 \\
\hline 6 & 1308 & $1.58 \%$ & 2661.2 & 1.13 & 75.0 \\
\hline 7 & 355 & $0.43 \%$ & 2704.0 & 1.13 & 96.2 \\
\hline 8 & 88 & $0.11 \%$ & 2873.8 & 1.13 & 112.9 \\
\hline 9 & 6 & $0.01 \%$ & 3087.1 & 1.09 & 112.6 \\
\hline 10 & 1 & $0.00 \%$ & 3973.4 & 1.08 & 106.6 \\
\hline \multicolumn{6}{|c|}{ Chinese airport network } \\
\hline 1 & 1329 & $22.33 \%$ & 995.3 & - & - \\
\hline 2 & 2705 & $45.45 \%$ & 1668.7 & 1.07 & 68.9 \\
\hline 3 & 1617 & $27.17 \%$ & 2394.8 & 1.11 & 42.6 \\
\hline 4 & 292 & $4.91 \%$ & 2939.4 & 1.14 & 78.6 \\
\hline 5 & 8 & $0.13 \%$ & 2839.6 & 1.12 & 87.8 \\
\hline
\end{tabular}

Table 4. Number of steps required and general features of the quickest connections (in terms of overall travel time), between pairs of airports. 


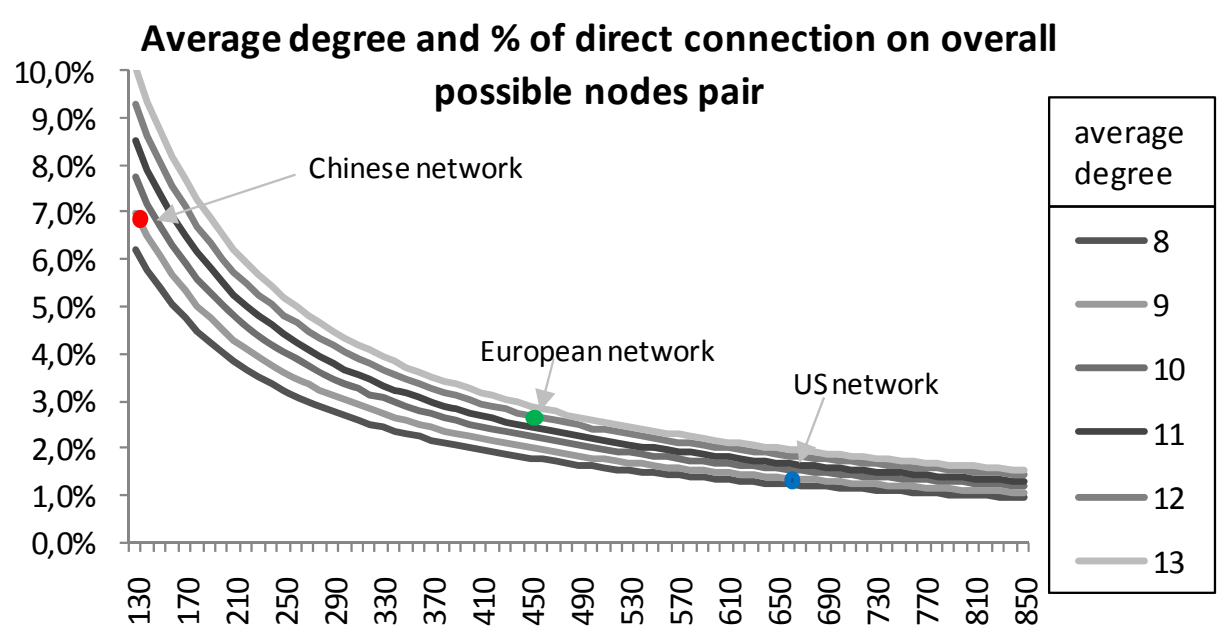

n. of airports

Figure 6. Share of the theoretical direct connections on overall origin-destination pairs as a function of the size of the network $(N)$ and the average nodes degree $(k)$.

Two-step and three-step paths are necessary for connecting distant airports. Indeed, average great circle distances is about $800-1,000 \mathrm{~km}$ for 1 step connection compared to $1.500-2.500 \mathrm{~km}$ in the cases of, two-step and three-step paths. Paths with more than four steps tend to have only a further slightly increases of the average great circle distance between origin and destination. These routes often connect minor airports that are not necessarily distant, but part of different and poorly interconnected sub-networks. We do not find paths longer than five steps in the Chinese network.

Surprisingly, even though the three networks have very different topological features, their average routing factors fall within a fairly narrow range (from 1.07 to 1.14 ) with very similar routing factor values also when compared by number of required steps. This similarity of routing factors is quite interesting, and suggests that connections with routing factor much higher than 1.1 will almost always have a better alternative. Table 4 thus provides some interesting insights into hub location and the performance of indirect connection even if it does not consider the effects of waiting times in intermediate airports.

Now let us introduce also these effects. Table 5 shows the average shortesttravel times for optimal routes with a given number of steps, including waiting times in intermediate airports. The average speed is defined as the total optimal travel time divided by the great circle distance. Thus, it represents the speed going straight to destination "as the crow flies" and requiring the same travel time. The shorter average distance of direct flights within Europe results in a lower average speed, 
which can be mainly attributed to the lower percentage of time spent at cruise velocity. For direct flights, we find an average speed close to $500-600 \mathrm{~km} / \mathrm{h}$.

For two-step paths the average speed falls to $270-300 \mathrm{~km} / \mathrm{h}$ due to circuitry times and waiting times in intermediate airports. Europe is the least efficient network with respect to waiting times; it averages two hours per connection, accounting for roughly $40 \%$ of total travel time. In US, where airlines widely exploit the "hub \& spoke" strategy on domestic routes, waiting times for two-step connections are on average shorter by 20 minutes. The Chinese network registers an average waiting time similar to that of the US network.

For three-step paths, waiting times increase by another 2 hours. More precisely, the average waiting time increases by 114 minutes in the US, 119 minutes in Europe, and 140 minutes in China. The ratio of flight time to total travel time drops to $53.5 \%$ in Europe, $55 \%$ in China, and $60 \%$ in the US. In terms of equivalent average speeds, the airline transportation systems become comparable to high-speed trains. When considering longer paths, in all three networks the ratio of flight time to travel time levels off at about $50 \%$ and the average speed levels off at $200 \mathrm{~km} / \mathrm{h}$. 


\begin{tabular}{|c|c|c|c|c|c|}
\hline $\begin{array}{l}\text { No. } \\
\text { steps }\end{array}$ & $\begin{array}{l}\text { No. of O-D } \\
\text { pairs }\end{array}$ & $\begin{array}{l}\text { Average travel } \\
\text { time (min) }\end{array}$ & $\%$ Flight time & $\begin{array}{l}\text { Waiting time } \\
\text { (min) }\end{array}$ & $\begin{array}{c}\text { Average "as a } \\
\text { crow flies" } \\
\text { speed }(\mathbf{k m} / \mathbf{h})\end{array}$ \\
\hline \multicolumn{6}{|c|}{ US airport network } \\
\hline 1 & 5488 & 118 & $100.0 \%$ & - & 521.5 \\
\hline 2 & 41833 & 319 & $67.9 \%$ & 102 & 328.9 \\
\hline 3 & 49191 & 542 & $60.1 \%$ & 216 & 279.9 \\
\hline 4 & 19760 & 683 & $56.1 \%$ & 299 & 249.8 \\
\hline 5 & 4286 & 772 & $54.6 \%$ & 350 & 232.6 \\
\hline 6 & 526 & 748 & $51.3 \%$ & 363 & 195.9 \\
\hline 7 & 157 & 710 & $51.3 \%$ & 346 & 186.5 \\
\hline 8 & 79 & 800 & $56.4 \%$ & 348 & 217.8 \\
\hline 9 & 12 & 696 & $56.0 \%$ & 306 & 187.4 \\
\hline \multicolumn{6}{|c|}{ European airport network } \\
\hline 1 & 5544 & 107.4 & $100.0 \%$ & - & 498.3 \\
\hline 2 & 23042 & 314 & $61.3 \%$ & 121 & 272.8 \\
\hline 3 & 32312 & 517 & $53.5 \%$ & 240 & 229.4 \\
\hline 4 & 15795 & 669 & $50.1 \%$ & 334 & 210.3 \\
\hline 5 & 4576 & 766 & $48.9 \%$ & 391 & 203.4 \\
\hline 6 & 1308 & 824 & $48.0 \%$ & 428 & 193.8 \\
\hline 7 & 355 & 888 & $47.5 \%$ & 466 & 182.7 \\
\hline 8 & 88 & 943 & $48.6 \%$ & 484 & 182.7 \\
\hline 9 & 6 & 994 & $48.7 \%$ & 509 & 186.3 \\
\hline 10 & 1 & 1245 & $47.0 \%$ & 660 & 191.5 \\
\hline \multicolumn{6}{|c|}{ Chinese airport network } \\
\hline 1 & 1329 & 97 & $100.0 \%$ & - & 618.8 \\
\hline 2 & 2705 & 353 & $70.2 \%$ & 105 & 283.8 \\
\hline 3 & 1617 & 544 & $55.0 \%$ & 245 & 264.1 \\
\hline 4 & 292 & 762 & $51.7 \%$ & 368 & 231.6 \\
\hline 5 & 8 & 761 & $51.5 \%$ & 369 & 224.0 \\
\hline
\end{tabular}

Table 5. Average quickest travel times, waiting times at intermediate airports, and speeds of optimal routes connecting airport pairs in the networks by the given number of steps.

For all departure-destination airport pairs, Figure 7 plots "as the crow flies" speed against the great circle distance. The number of steps is indicated by color, with direct flights in dark blue. Equivalent speeds are highest for direct, long-distance flights, which approach $800 \mathrm{~km} / \mathrm{h}$ in all three networks. This is a typical cruise speed for short- and medium-haul aircrafts. The more steps in the route, however, the lower the equivalent speed. Note that among routes with more than four steps, the relationship between distance and speed becomes linear. All three networks have very similar features. The Chinese network shows a sparser distribution due to its much lower number of airport pairs. 


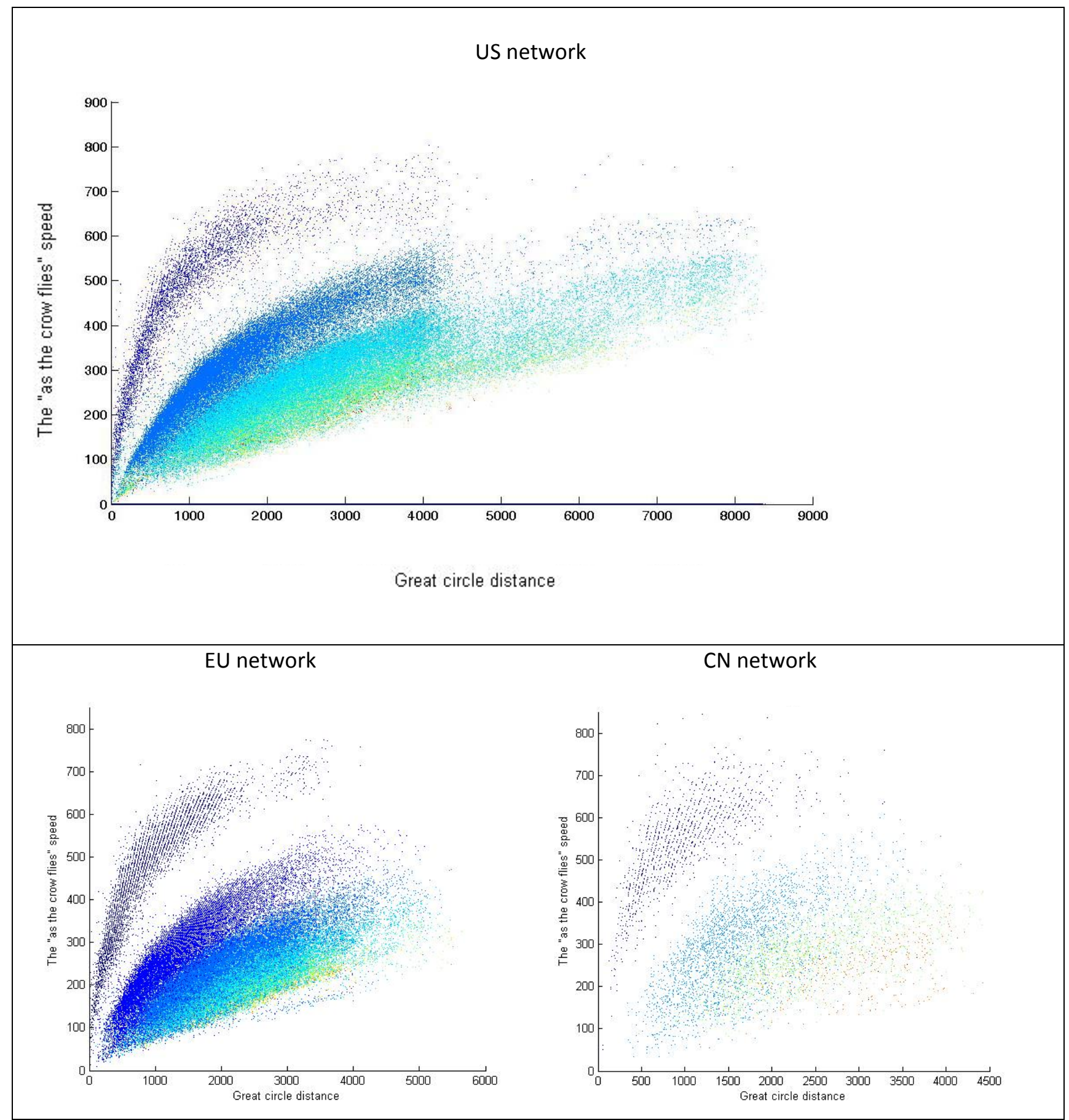

Figure 7. The relationship between the equivalent "as the crow flies" speed and great circle distance as a function of the number of steps, plotted separately for all three networks. The dark blue dots represent direct (one-step) paths. Progressively lighter shades represent more steps.

In order to account for the size of the airports connected by each O-D links, we also calculate a weighted average of quickest connection waiting times. For direct flights, the waiting time is zero. The weighting factor for all routes, including direct flights, is the total size (annual seats offered) of the departure and destination airports. 
The results of this analysis (see Table 6) show shorter waiting times at all levels, since connections to major airports are generally better projected and coordinated.

For example, two-step paths in Europe require an average waiting time of 121 minutes, but the weighted average is only 94 minutes. The US network is most efficient at managing two-step connections, with an weighted average waiting time of only 72 minutes.

Moreover, the role of long-path connections is far less important, meaning that long paths tend to be necessary only between very small airports.

On average, connections with long waiting times are between small airports. In this case, Europe shows the highest weighted waiting time, 48.5 minutes,

\begin{tabular}{|c|c|c|c|c|c|c|}
\hline \multirow[b]{2}{*}{ No. steps } & \multicolumn{2}{|c|}{ US } & \multicolumn{2}{|c|}{$\mathbf{E U}$} & \multicolumn{2}{|c|}{$\mathbf{C N}$} \\
\hline & $\begin{array}{l}\text { Weighted } \\
\text { waiting time }\end{array}$ & $\begin{array}{c}\text { contribution } \\
\text { to overall } \\
\text { average } \\
\end{array}$ & $\begin{array}{c}\text { Weighted } \\
\text { waiting time }\end{array}$ & $\begin{array}{c}\text { contribution } \\
\text { to overall } \\
\text { average } \\
\end{array}$ & $\begin{array}{c}\text { Weighted } \\
\text { waiting } \\
\text { time } \\
\end{array}$ & $\begin{array}{c}\begin{array}{c}\text { contribution } \\
\text { to overall } \\
\text { average }\end{array} \\
\end{array}$ \\
\hline 1 & 0 & $60.9 \%$ & 0 & $57.32 \%$ & 0 & $79.3 \%$ \\
\hline 2 & 76 & $36.0 \%$ & 94 & $35.79 \%$ & 92 & $18.1 \%$ \\
\hline 3 & 165 & $2.8 \%$ & 202 & $5.86 \%$ & 217 & $2.4 \%$ \\
\hline 4 & 251 & $0.2 \%$ & 293 & $0.83 \%$ & 320 & $0.2 \%$ \\
\hline$>4$ & 320 & $0.0 \%$ & 359 & $0.20 \%$ & 397 & $0.0 \%$ \\
\hline $\begin{array}{l}\text { Average } \\
\text { weighted } \\
\text { waiting time }\end{array}$ & 32.8 & & 48.5 & & 22.5 & \\
\hline
\end{tabular}

Table 6. Weighted average of quickest path waiting times (in minutes) for each network. The weighting factor is the total size of the origin and destination airports.

\subsection{Travel time and secondary airports}

In the last part of the empirical analysis, we compare the relative accessibility of primary and secondary airports in the three networks. Figure 8 reports the probability of reaching a given fraction of the network by departing from any airport with fewer than $k$ direct connections. The total rise in this cumulative distribution reflects the role played by small and large airports in the network. The greatest difference is found in the Chinese network, where on average the probability of reaching a given portion of the network increases by about 15\% passing from small airports to bigger airports. The US network is much more homogeneous, but the probability of reaching a given fraction of the network is on average lower than in the EU or China. 
In Europe as in the US, the accessibility of the network doesn't change much with airport size. On the other hand, there are great differences in the absolute level of accessibility within Europe. The probability of reaching $70 \%$ of the network is about $50 \%$ for airports with less than 30 direct connections, but his figure drops to less than $10 \%$ if one desires to reach $90 \%$ of the network.

For example, Considering airport with less than 15 direct connection $1 / 5$ airports reach $90 \%$ of the network as a whole in US , 1/10 in $\mathrm{CN}$ and 1/16 in EU; opposite in $\mathrm{CN}$ and in $\mathrm{EU} 7 / 10$ airports reach at least $30 \%$ of the network while in US less than $6 / 10$.

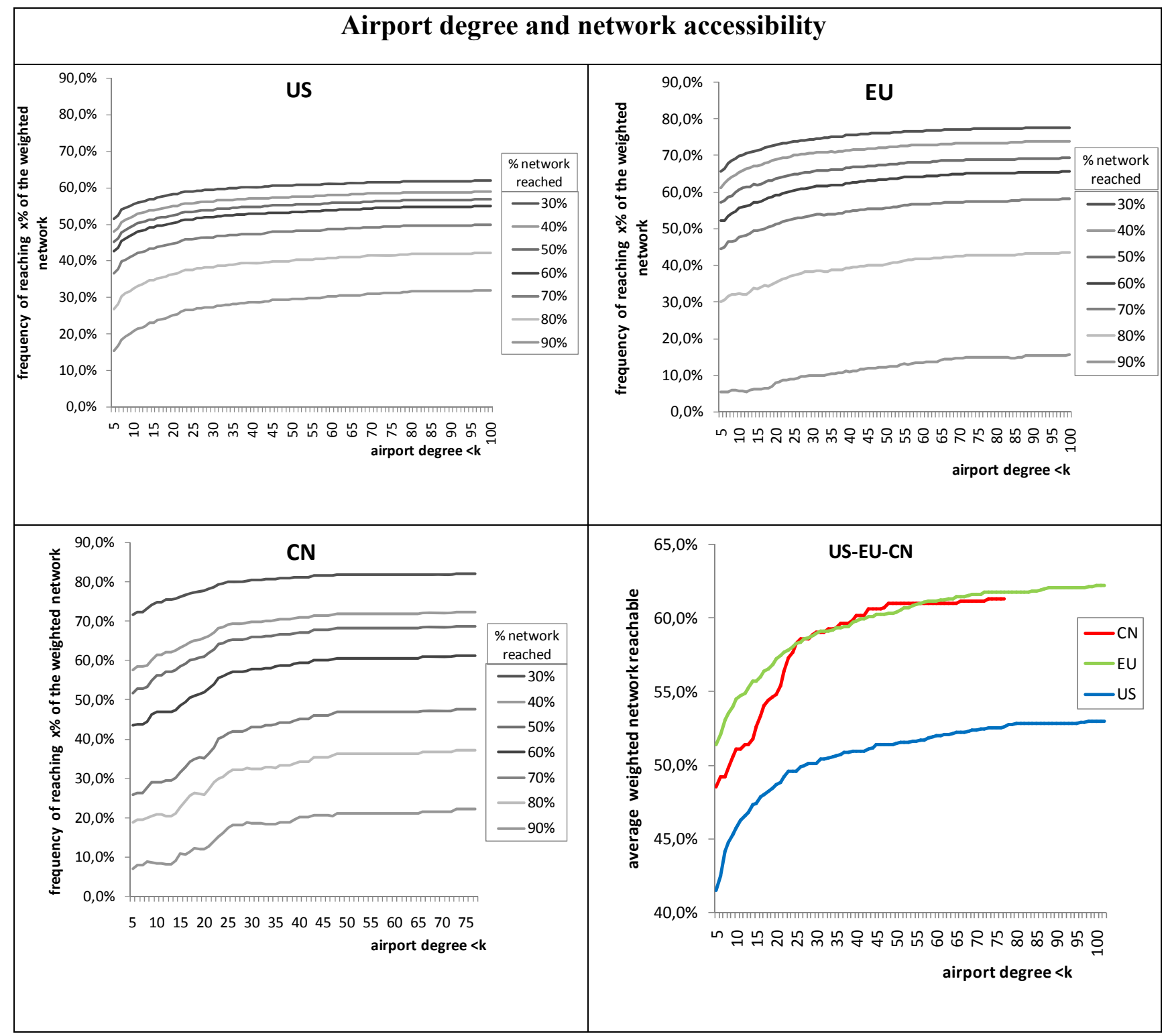

Figure 8. Airport degree and network accessibility. 
Table 7 specifies the number of airports reachable in one day and average waiting times as a function of origin-destination airport sizes. The airports in the network are divided into four quartiles based on the number of direct connections, with Group 4 airports having the most. Thus, a passenger starting from one the biggest airports can reach the vast majority (over 90\%) of airports classified in the same quartile. This figure reaches $96 \%$ for the US network. On the other hand, for a passenger departing from a small airport (Group 1) in the US, the probability of reaching any final destination of the same dimension by midnight of the same day is less than $5 \%$. The European and Chinese networks perform significantly better for small airports by this measure. The probability of reaching a Group 4 airport starting from a Group 1 airport is 51\% in the EU, and 34\% in China. It appears that most small airports in the US are located in very remote areas or are very poorly connected to the rest of the network.

Dividing routes in the same manner, we see that connections between the largest airports result in the shortest waiting times. When both origin and destination airports belong to Group 4, average waiting times are less than 40 minutes in all three networks. This low value is not surprising, since most of the connections between major airports are served by direct flights. The EU network has higher waiting times than the US network overall. One can relate this finding to the higher percentage of airports reached in one day; there is a trade-off between the "openness" of the network and the average waiting time spent in intermediate airports. 


\begin{tabular}{|c|c|c|c|c|c|c|c|c|c|}
\hline \multicolumn{5}{|c|}{ Percentage of airports reachable in one day } & \multicolumn{5}{|c|}{ Average waiting times } \\
\hline \multicolumn{10}{|l|}{ US } \\
\hline $\mathrm{O} / \mathrm{D}$ & Group 1 & Group 2 & Group 3 & Group 4 & $\mathrm{O} / \mathrm{D}$ & Group 1 & Group 2 & Group 3 & Group 4 \\
\hline Group 1 & $5 \%$ & $1 \%$ & $3 \%$ & $4 \%$ & Group 1 & 162 & 336 & 247 & 357 \\
\hline Group 2 & $2 \%$ & $19 \%$ & $36 \%$ & $53 \%$ & Group 2 & 176 & 323 & 271 & 181 \\
\hline Group 3 & $3 \%$ & $36 \%$ & $62 \%$ & $79 \%$ & Group 3 & 301 & 263 & 209 & 126 \\
\hline Group 4 & $4 \%$ & $57 \%$ & $84 \%$ & $96 \%$ & Group 4 & 208 & 139 & 97 & 32 \\
\hline \multicolumn{10}{|l|}{$\mathbf{E U}$} \\
\hline $\mathrm{O} / \mathrm{D}$ & Group 1 & Group 2 & Group 3 & Group 4 & $\mathrm{O} / \mathrm{D}$ & Group 1 & Group 2 & Group 3 & Group 4 \\
\hline Group 1 & $12 \%$ & $19 \%$ & $30 \%$ & $51 \%$ & Group 1 & 393 & 339 & 279 & 205 \\
\hline Group 2 & $17 \%$ & $27 \%$ & $39 \%$ & $58 \%$ & Group 2 & 396 & 332 & 280 & 190 \\
\hline Group 3 & $25 \%$ & $38 \%$ & $50 \%$ & $71 \%$ & Group 3 & 379 & 283 & 219 & 114 \\
\hline Group 4 & $44 \%$ & $58 \%$ & $71 \%$ & $91 \%$ & Group 4 & 237 & 166 & 113 & 38 \\
\hline \multicolumn{10}{|l|}{$\mathrm{CN}$} \\
\hline $\mathrm{O} / \mathrm{D}$ & Group 1 & Group 2 & Group 3 & Group 4 & $\mathrm{O} / \mathrm{D}$ & Group 1 & Group 2 & Group 3 & Group 4 \\
\hline Group 1 & $4 \%$ & $6 \%$ & $17 \%$ & $34 \%$ & Group 1 & 326 & 360 & 352 & 243 \\
\hline Group 2 & $6 \%$ & $10 \%$ & $20 \%$ & $45 \%$ & Group 2 & 335 & 357 & 295 & 173 \\
\hline Group 3 & $16 \%$ & $19 \%$ & $46 \%$ & $77 \%$ & Group 3 & 250 & 257 & 215 & 79 \\
\hline Group 4 & $36 \%$ & $48 \%$ & $76 \%$ & $93 \%$ & Group 4 & 127 & 103 & 86 & 13 \\
\hline
\end{tabular}

Table 7. Percentage of airports reachable in one day and average waiting times in intermediate airports. Airports are grouped into quartiles based on the number of connections, where Group 4 contains the most connected airports. Each origin-destination (O/D) pair is classified according to the categories of its airports, as shown on the rows and the columns of the table, before the average is calculated. In the average, O-D pairs are weighted by the total size of the connected airports.

\section{Conclusion}

Our study compares the airport networks of the US, Europe and China in terms of accessibility and shortest travel times (including waiting time at intermediate airports). A topological analysis confirms that all three networks belong to the small world class, with similar degree distributions 
and clustering coefficients. In order to account for travel times and scheduling coordination, we calculate departure time-dependent minimum paths between each airport pair in a network. We also evaluate the quality of indirect connections in terms of circuitry times and routing factors. Our results show that the three networks do not differ much in terms of routing factors and circuitry times. About a third of the possible connections may be successfully concluded within a single day, following a quickest path whose routing factor does not exceed 1.25. The European network reaches the highest percentage of destinations, at $39.1 \%$.

We assess the temporal coordination of flights by calculating waiting times in intermediate airports. The analysis shows that waiting times for indirect connections account for between $30 \%$ and $50 \%$ of the overall travel times. Even though the European network has the greater number of direct flights per airport, connections requiring intermediate airports require average waiting times exceeding those of the American and Chinese networks.

Our analysis does not support a preference for one network over the others. Nevertheless, we do find evidence for a trade-off between the "openness" of the network and the average waiting times spent at intermediate airports. In Europe, the policies of individual governments might explain the high percentage of airports accessible within a single day: each country favors connectivity towards its own local airports. Such policies reduce the efficiency of coordination between countries, resulting in higher waiting times. In contrast, the US network shows better coordination (having benefited from a longer liberalization history) even though its routes to secondary airports have gradually been marginalized. 


\section{References}

Amaral, L. A. N., Scala, A., Barthelemy, M., Stanley, H. E., 2000. Classes of small-world networks. Proceedings of the National Academy of Sciences of the United States of America. 97, 11149:1-4.

Albert, R., Barabási, A.L., 2002. Statistical mechanics of complex networks. Reviews of Modern Physics. 74, 47-97.

Bagler, G., 2004. Analysis of the Airport Network of India as a complex weighted network. arXiv:cond-mat/0409773.

Barabasi, A.L., Albert, R., 1999. Emergence of scaling in random networks. Science. 286, 509-512.

Barrat, A., Barthélemy, M., Vespignani, A., 2004. Modeling the evolution of weighted networks. Physical Review E. 70, 066149:1-12

Burghouwt, G., de Wit, J., 2005. Temporal configurations of European airline networks. Journal of Air Transport Management. 11(3), 185-198.

Burghouwt, G., 2007. Airline Network Developments in Europe and its Implications for Airport Planning. England: Ashgate.

Freeman, L.C., 1977. A set of measures of centrality based on betweenness. Sociometry 40, 35-41.

Costa, L., Silva, F.N., 2006. Hierarchical Characterization of Complex Networks. Journal of Statistical Physics. 125(4), 845-876.

Guida, M., Funaro, M., 2007. Topology of the Italian airport network: A scale-free small-world network with a fractal structure?. Chaos, Solitons \& Fractals. 31(3), 527-536.

Guimerà, R., Mossa, S., Turtschi, A., Amaral, L.A.N., 2005. The worldwide air transportation network: Anomalous centrality, community structure, and cities' global roles. Proceedings of the National Academy of Sciences of the United States of America. 102(22), 7794-7799.

Guimerà, R., Sales-Pardo, M., Amaral, L.A-N., 2007. Classes of complex networks defined by roleto-role connectivity profiles. Nature Physics. 3, 63-69.

Latora, V., Marchiori, M., 2001. Efficient Behavior of Small-World Networks. Physical Review Letters. 87(19), 198701:1-4.

Li, W., Cai, X., 2004. Statistical Analysis of the Airport Network of China. Physical Review E. 69, 046106 1-6. 
Malighetti, P., Paleari, S., Redondi, R., 2008. Connectivity of the European airport network: 'selfhelp hubbing' and business implications. Journal of Air Transport Management. 14, 53-65.

Milgram, S., 1977. The small world problem. In: Milgrim, S., Sabini, J., (Eds), The Individual in a Social World: Essays and Experiments. Reading, MA: Addison-Wesley, 281-295.

Miller-Hooks, E., Patterson, S.S., 2004. On Solving Quickest Time Problems in Time-Dependent, Dynamic Networks. Journal of Mathematical Modelling and Algorithms. 3, 39-71.

Reed, W. J., 2003. The Pareto law of incomes - an explanation and an extension. Physics A. 319, 469-486.

Veldhius, J.,1997. The competitive position of airline networks. Journal of Air Transport Management. 3(4), 181-188.

Watts, D.J., Strogatz, S.H., 1998. Collective Dynamics of 'Small-World' Networks. Nature. 393(4), 440-442.

Watts, D. J., 1999. Small Worlds: The Dynamics of Networks Between Order and Randomness. Princeton, NJ: Princeton Univ. Press. 